\title{
The Transformation and Reconstruction of Rural Value from the Perspective of the Sense of Place -Take Kaiping Fang Clan as an Example
}

\author{
Yiwei Chen ${ }^{1}$, Tian Yang ${ }^{2 *}$, Xinglin $\mathrm{Li}^{3}$ and Wenbo $\mathrm{Li}^{1}$ \\ ${ }^{1}$ School of Civil Engineering and Architecture Wuyi University China \\ ${ }^{2}$ Guangdong Qiaoxiang Culture Research Center, Wuyi University, China \\ ${ }^{3}$ School of Foreign Languages Wuyi University China
}

*Corresponding author: Tian Yang, Guangdong Qiaoxiang Culture Research Center, Wuyi University, China.

\begin{abstract}
In the discussion of the relationship between globalization and localization, Jiangmen Qiaoxiang makes the regional characteristics of reciprocity and reconstruction of south China clans appears particularly prominent. This study explores the rural value transformation, traditional revival and reconstruction of villages from the theoretical perspective of local sense, combined with regional cultural characteristics in the Qiaoxiang region. This paper also discusses the reconstruction and transformation of rural value of heritage sites in the process of Kaiping's transformation from Qiaoxiang to the world cultural heritage site. Thus, from nativity to sense of place, cultural heritage exhibition and reconstruction of sense of place is an important practice to deal with the transformation of social modernity.
\end{abstract}

Keywords: Sense of place; Rural value; Overseas chinese; Qiaoxiang

\section{Introduction}

Since the Reform and Opening up, China's urbanization level has been continuously improved, with the urbanization level jumping from $19 \%$ in 1980 to $60.60 \%$ in 2019 . Under the strong national political context of "to take economic construction as center", rural economic development gave way to urban economic development, and a large number of farmers abandon their land in the countryside, laid down their agricultural tools and left their hometown to enter the city. The economic structure, demographic characteristics and governance model of the rural society are changing. The old order has been destroyed, and the new paradigm has not been established [1]. The subjectivity of peasants is gradually lost, and they were thrown into an embarrassing situation where the tradition had been lost and the modern could not be obtained, which led to a general sense of powerlessness, rootlessness and anxiety. Economic and cultural development, however, is based on the economic foundation, and culture from the perspective of historical materialism, as a kind of "conceptual superstructure", is regulated and restricted by the economic foundation [2]. In this sense, urban culture is defined as the progressive mainstream culture, while rural culture is defined as the backward and decadent feudal culture. Hence, rural culture loses its discourse power in the competition with urban one, and is gradually marginalized, thus it makes peasants fall into the identity crisis. The cultural tendency of social groups is constantly divided, the mutual relationship between social groups is reconstructed, and the local identity is also in a process of continuous re-imagination and re-interpretation [3]. 
In the discussion of the relationship between globalization and localization, Jiangmen Qiaoxiang - hometown of overseas Chinese-makes the regional characteristics of reciprocity and reconstruction of south China clans appear particularly prominent. The local characteristics of "overseas Chinese" are formed in the globalization of population and culture, but they are also challenged by globalization [4]. People's local identity is gradually weakened in the context of globalization, and the universal construction of Chinese cities makes local characteristics gradually disappear. Globalization has brought time-space compression, which enables economic and cultural forces to overcome the traditional space and time constraints and reconstruct the construction of space and place on a larger scale [5].

In 2007, Kaiping Diaolou and villages became the 35th World heritage site in China and the only Cultural World heritage site for Overseas Chinese in the world. The local government has vigorously integrated the cultural resources of Huaqiao to develop heritage tourism, which has attracted a large number of domestic and foreign tourists and overseas Chinese who come to seek their roots and ancestors. Kaiping Diaolou and villages has become the name card of Kaiping city and even Wuyi region. However, what changes have taken place in Kaiping's rural value system from the Qiaoxiang to the world cultural Heritage site? How has local villagers' perception of the Diaolou changed from ancestral house to heritage? These questions have become the focus of this study.

\section{Review of Place Theory}

Place theory is an important theoretical perspective of contemporary human geography. In 1974, the human geographers represented by Duan Yifu first introduced the concept of "place" into human geography [6]. After the concept of "place" was introduced, core concepts such as sense of place, place attachment, place identity and place dependence were proposed successively. The sense of place is the product of the interaction between people and places, which is an experience generated by places and endowed by people. To some extent, people create places. Places cannot exist independently without people, and they are strongly related to each other and can reinforce each other's personality [7]. In this sense, space forms the place after the emotional exchange with people, and the difference between place and space lies in the human dimension. So far, the concept of sense of place has formed a relatively complete research system in human geography and environmental psychology, but there are still differences in the definition of the relationship between the concepts, and there are mainly two directions: some scholars think it is a whole concept, with only hierarchical differences; while some others believe that it is a multi-dimensional concept with differences in dimensions and hierarchies. The common dimensions are local attachment, local identity and local dependence [8]. Dai (2019), on the basis of systematic review of relevant literature, sorted out five logical relationships among local attachment, local identity and local dependence: local identity and local dependence are equivalent; Local identity and local dependence coexist; the coexistence of local attachment, local identity and local dependence is the sub-dimension of the sense of place. Local attachment and local identity are mutually independent [9]. In short, local sense is an inclusive concept, which refers to people's specific emotional attachment and identity, mainly including local attachment and local identity [10]. Place attachment, refers to a kind of cognitive or emotional connection of the individual to place and their living environment, is an emotional feeling. Furthermore, it hopes to integrate the sense of place into the place of emotional attachment in space and keep a relatively close distance with the place of emotional attachment in space [11]. The concepts of local identity and local attachment are often used interchangeably in studies, and they are considered to be equivalent. In 1983, Proshansky brought the concept of identity into the context of environmental psychology. He emphasized that local identity is a part of self-identity and is a complex interaction of ideas, beliefs, preferences, emotions, values, goals, behavioral trends and skills that exist consciously and unconsciously. People acquire a sense of belonging through their attachment to places in a geographical sense, which gives meaning to life [12]. Only by clarifying the coordinates of individual or group identity in a spatial significance system, and individual or social group, can self-identity and self-interpretation be fully understood [13].

From the existing domestic literature, most of the research on rural value issues is conducted from the perspectives of rural economy, politics and tourism economy, but few studies are conducted from the perspective of local sense. This study explores the rural value transformation, traditional revival and reconstruction of villages from the theoretical perspective of local sense, combined with regional cultural characteristics in the Qiaoxiang region: Tangkou Village, Sangyuan Village and Miaobian Village in Kaiping Tangkou Town.

\section{Research Areas and Methods}

Kaiping Diaolou and Village is located in Kaiping city under the jurisdiction of Jiangmen City, in the south-central part of Guangdong Province, southwest to the part of the Pearl River Delta. It spans latitude $21^{\circ} 56^{\prime} \sim 22^{\circ} 39^{\prime}$ north and longitude $112^{\circ} 13^{\prime} \sim 112$ ${ }^{\circ} 48^{\prime}$ east. It is connected with Xinhui in the northeast, with Heshan in the north, Taishan in the southeast, Enping in the southwest, and Xinxing in the northwest. Kaiping city covers a total area of 1,659 square kilometers, with 267 villages (communities) and 2,726 natural villages, and a population of 688,900. On June 28, 2007, Kaiping Diaolou and villages were officially included in the World Heritage List at the 31st Heritage Conference held in New Zealand, becoming the 35th World Heritage site in China and the only Cultural World Heritage site of overseas Chinese in the world. There are 1,833 existing Diaolou in Kaiping, and the public Diaolou attractions include The Ancient Village of Ma Jianglong, the Diaolou group of Jinjiangli, the South Tower, the Diaolou Group of Zili Village, the Liyuan village 
and the Sanmenli Village. Kaiping Diaolou and villages have distinct characteristics of the fusion of local culture and foreign culture, and relatively complete preservation of the history of the original space and cultural imprint. The main fieldwork areas in this paper are Tangkou Village, Sangyuan Village, Miaobian Village and surrounding areas in Guzhai area, under the management of the village committee of Qiangya Village and Zhaqun Village. The local residents are mainly Fang clan people.

This study adopts the research methods of network archive analysis, semi-structured interview, literature review and participant observation. The research team also collect document on Kaiping Diaolou and villages based on historical documents (mainly includes the classical literature Kaiping County Annals and Guzhai Monthly, etc.), local Chronicles and other investigation. In addition, starting with the local sense, this study conducted interviews on the perspective of rural value transformation and reconstruction under the background of Kaiping Diaolou heritage and Qiaoxiang culture.

\section{The Shaping of Sense of Place and the Construction of Local Meaning}

\section{The sense of place of ancestral hall is shaped by blood ties}

The ancients said: "When a virtuous man establishes a habitat, he takes the ancestral temple as the first place, where most of the branches of clans are originated." Ancestral hall is regarded as the starting point of the origin of the clan, and is often the center of the rural geographical location, with the functions of ancestor worship, festival celebration, banquet and other clan activities. At the same time, ancestral halls are often equipped with good public facilities and transportation conditions to provide residents with good public living space. Therefore, ancestral hall is the center of local villagers' geographical location and psychological emotion, maintaining a stable clan relationship. According to the annals of Kaiping County, "Starting from Song and Yuan Dynasty, the ancestor of Fang clan was from Putian county, Fujian province. They moved to the west of the city of Nanhai, Guangdong province because their ancestor was served as an official. The eldest son, Dao Sheng, who moved to Maogang from The west of Nanhai City, is the ancestor of the Fang clan in Kaiping County. Hence his descendants live in the Guzhai area in Tangkou Town". In this sense, the Fang clan from Tangkou village, Sangyuan Village and Miaobian Village share the same blood common cultural customs and beliefs. According to local villagers, every village will set up a large banquet in front of the ancestral hall every year on the sixth day of the Lunar New Year, which is called "lantern banquet".

"Every year on the sixth day of the Spring Festival, the villagers gather to eat together. The money for the banquet was raised together. Each villager will donate money according to their own actual situation, the amount of 50 yuan, 100 yuan ...There is red paper with lists of donor's on the wall at the entrance to the hall over there, You could go there and have a look......The banquet was organized by village cadres and production teams... Some people who have left the country will come back, and some people who are not free to come back will transfer some money to the organizers through Wechat.

The lantern banquet is an annual event in the village of Fang's clan. The funds for the lantern banquet were raised by village cadres, and the banquet scale reached more than 100 seats. On this day, the villagers who work abroad and immigrate abroad will also return to the village to participate in activities. Overseas Chinese who cannot return to the village will also choose to transfer funds to express their feelings. Before the banquet, the "lighting" ceremony was held; the villagers then worshipped the Shengmu Goddess in the ancient ancestral hall (Picture 1). Lantern has the meaning of light transmission, and the villagers hope that the family clan will continue and prosper through worship. As the villagers of Sangyuan village said:

"When a child is born for a full month, its parents will come to the temple to mount the incense and light the lantern for it. While some unreachable overseas Chinese will ask their acquaintances in the village to help them do it when their child is born for a full month."

When villagers participate in the lantern banquet and worship the Shengmu Goddess, the visual landscape and strong local atmosphere generated by specific body rhythm can be embodied by local participants. The individual's experience and response to spatial emotions also promotes them to actively turn their body dynamics and socialization into a space for festival performances. The reproduction of body space year after year has continued to maintain and reproduce the time space of the festival, and to construct a local identity with a common sense of belonging [14]. Lantern banquet is a channel for villagers to construct their self-identity through clan festivals. Young people who have left their hometown and those who have gone abroad maintain and renew their own clan belief and clan identity in the festival space and atmosphere of the Lantern banquet, and at the same time, they construct their own local identity to their hometown villages. After the lantern banquet, the villagers of Tangkou village will take a group photo of the whole village in front of the ancestral hall. Every year, the group photo of the whole village is hung in the ancestral hall. The group photo of the whole village becomes the material witness of this process, which continues to affect the emotional space of the villagers and maintain the stability of the clan.

Besides the function of undertaking collective activities, ancestral hall is also a space for villagers' emotional communication in daily life. In the process of field investigation, we found that the villagers like to chat in the open space in front of the ancestral temple. Some villagers are handling vegetables, while others are lying on benches for a rest. When they hear the topics of interest, they put in a few words. Through the continuous interaction process with the place, the place becomes a key element of self-definition [13]. The villagers' daily repeated chatting habits have not naturally enriched 
the local context, formed a unique collective memory, and passed the cultural memory and family memory of Fang clan between generations.

"The collective memory of an individual comes from the group memory in a specific social situation, thus contributing to the shaping of individual cultural identity... In order to consolidate group cohesion, many activities in social groups are used to strengthen collective memory" [15]. The ancestral hall is the space bearing place of Fang's clan with unique collective memory value symbol. It carries the common historical memory and family memory of Fang family at home and abroad. Under its value system, it forms a set of local identity and behavior logic which is linked by clan blood and geography. Meanwhile, ancestral hall provides a space exchange field for villagers' emotional expression, psychological perception and behavior experience in the process of daily material production and reciprocity. Traditional rural society takes blood relationship as the link. Villagers take ancestral hall as the core in their daily life. Through rituals and family sacrifices, they repeatedly exchange individual memory and reconstruct and awaken the localized collective memory. Therefore, the ancestral hall space is endowed with human emotion, which makes the space change from an abstract concept to a cultural carrier with practical significance. As Fei Xiaotong pointed out: "the unity of blood and geography is the original state of community" [16]. Therefore, the construction of rural sense of place is inseparable from the preservation of blood relationship and collective memory.

\section{The construction of sense of place under the power of transnational clan}

Kaiping belongs to Wuyi area, which is a famous Qiaoxiang in China. The formation and development of Qiaoxiang contains a wide range of social and cultural processes. For a long time, the overseas migration and overseas relations not only have a profound impact on the economic and social concepts, but also show the continuous shaping of the social life and customs and culture of Qiaoxiang [17]. According to the interviews, it is found that the local community still maintains the mutually beneficial relationship between Fang's clan members at home and abroad through the publication and distribution of the Guzhai monthly, a clan magazine at home and abroad. As a collective family letter linking Fang's clan at home and abroad, Guzhai monthly reflects the continuous interaction between overseas Chinese and their home countries. Through tracing the origin of the family history, Fang clan has social and cultural feedback and interaction on the traditional rejuvenation and familism in terms of space expansion and time continuity.

"Once, I talked with several villagers in Tangkou Market. During the conversation, we raised questions about whether the Fang surname was originated from Ji according to the previous period 'Kaiping weekly newspaper.' Why is it different from the Genealogy? Who is right? I take some information with this question and I hereby arrange as follows ...... I think it is still based on the genealogy. Because, when Fang Shu was Shangqing official rank) in Zhou Dynasty, he was already surnamed Fang. It is not that Empire Zhou xuanwang who named his descendants Fang as their surname..."

\section{-_Excerpted from the column "Local Stories" in the 22nd issue of Guzhai Monthly}

Fangs trace and revise the clan history by setting up a history column to solicit contributions. The exploration of collective memory has become the blood bond of resonance and empathy within the clan. In addition, the journal also reported the happy events and funerals of villagers on weekdays.

"It's a great pleasure for Yiwang to be a father-in-law again. Rong Kuan, the fifth son of Yiwang, living in the east gate of Miaobian village, worked in the Power Supply Station of Tangkou Town, married a girl surnamed Xie. They have got married on March 4 this year and hold a banquet at home to entertain uncles, aunts and friendly relatives and friends. The scene is very lively.

\section{_-Excerpted from the column "Rural Information in Guzhai} area" of 45 issue of "Guzhai Monthly"

As early as the 1920s, the Fang clan has been spread all over the world. Besides being assigned to local villagers, Guzhai monthly has also been sent to overseas fangs. There are social committees and contacts in the United States, Canada, Thailand, Singapore, Philippines, Hong Kong and Macao, and a general Fang family tracing hall is set up in the United States. The head office of Guzhai monthly is in Kaifang's hometown. Its correspondent is especially responsible for contacting overseas Fang's clan. In addition to ensuring the daily operation of Guzhai monthly, it is also responsible for maintaining clan relations at home and abroad. In addition, at the end of each issue, there are two forms, namely, the statement of financial income settlement and the financial report of library. Besides RMB,there are a large number of US dollar,Canadian dollar,Hong Kong dollar and so on. The kinship at home and abroad condensed and nurtured the blood identity of their hometown by contributing articles to the monthly magazine and donating money and materials. In the tide of globalization, the patriarchal clan emotion is strongly impacted by the multi culture. Although the relationship between overseas Chinese and domestic clans will decrease with the change of generations and the blurring of family memory, the connotation of homesickness and clan identity formed by the pull of overseas Chinese's geography and blood relationship to overseas Chinese is the sharing of nostalgia and clan identity. The transnational inflow and outflow of capital is not only the capital generated in the process of flow practice, but also the cultural experience and the feedback after it. Many of the capital earned by overseas family enterprises and migrant workers also return to the place where the clan started to reconstruct the clan relationship and construct the place [18]. Local villagers and overseas Chinese pay close attention to the development of clans in Qiaoxiang through Guzhai monthly and will send funds back to China to support the construction of their home- 
town through the family magazine. At the end of each issue, we will see the Fang's overseas Chinese family members made donations to build roads, repair ponds, engage in public welfare, set up family activities and improve the water supply system:

"Mr. Fang Junxue, from Sangyuan Village, traveling in Canada, accompanied Mr. Liu zhaoheng, Consul General of Canada in Guangzhou, on a visit to Kaiping in February this year, and was warmly welcomed by Kaiping municipal leaders. Fang Junxue is the president of International Resources of Canada..... He owns two companies and three warehouses in Vancouver, with an annual turnover of 20 million yuan, becoming a local businessman......He contributed gener- ously to local public welfare undertakings such as Dengliao Temple, Shude school and Guzhai monthly in Sangyuan village. "

\section{- Excerpted from the 45 issue of Guzhai monthly.}

Guzhai monthly is an important channel for information communication between Qiaoxiang and overseas Chinese communities. It enables local villagers and overseas Chinese family members to understand the basic situation of both sides through text reading. It constructs a direct economic and cultural channel, realizes the construction and maintenance of local significance based on clan identity, and completes self-identity and positioning at the individual level (Picture 2).

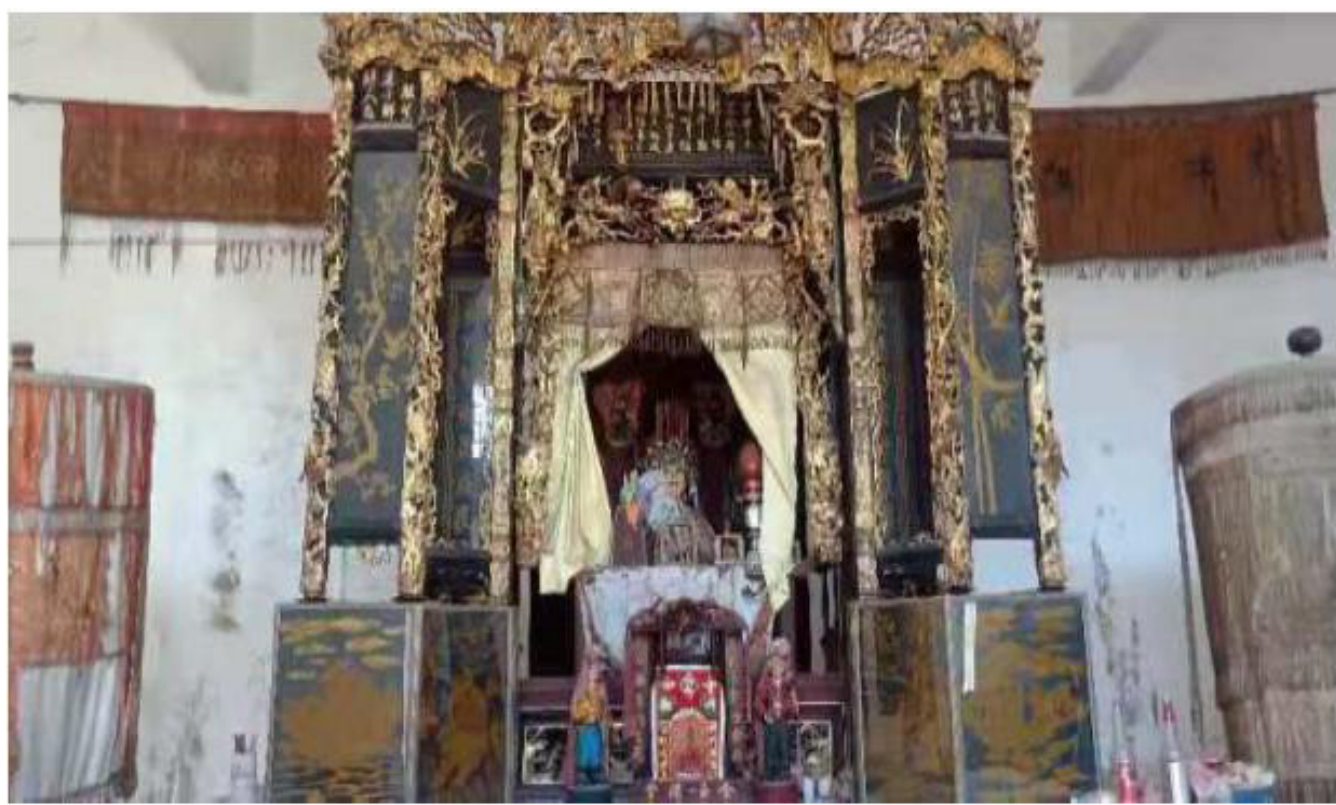

Picture 1: Shengmu Goddess.

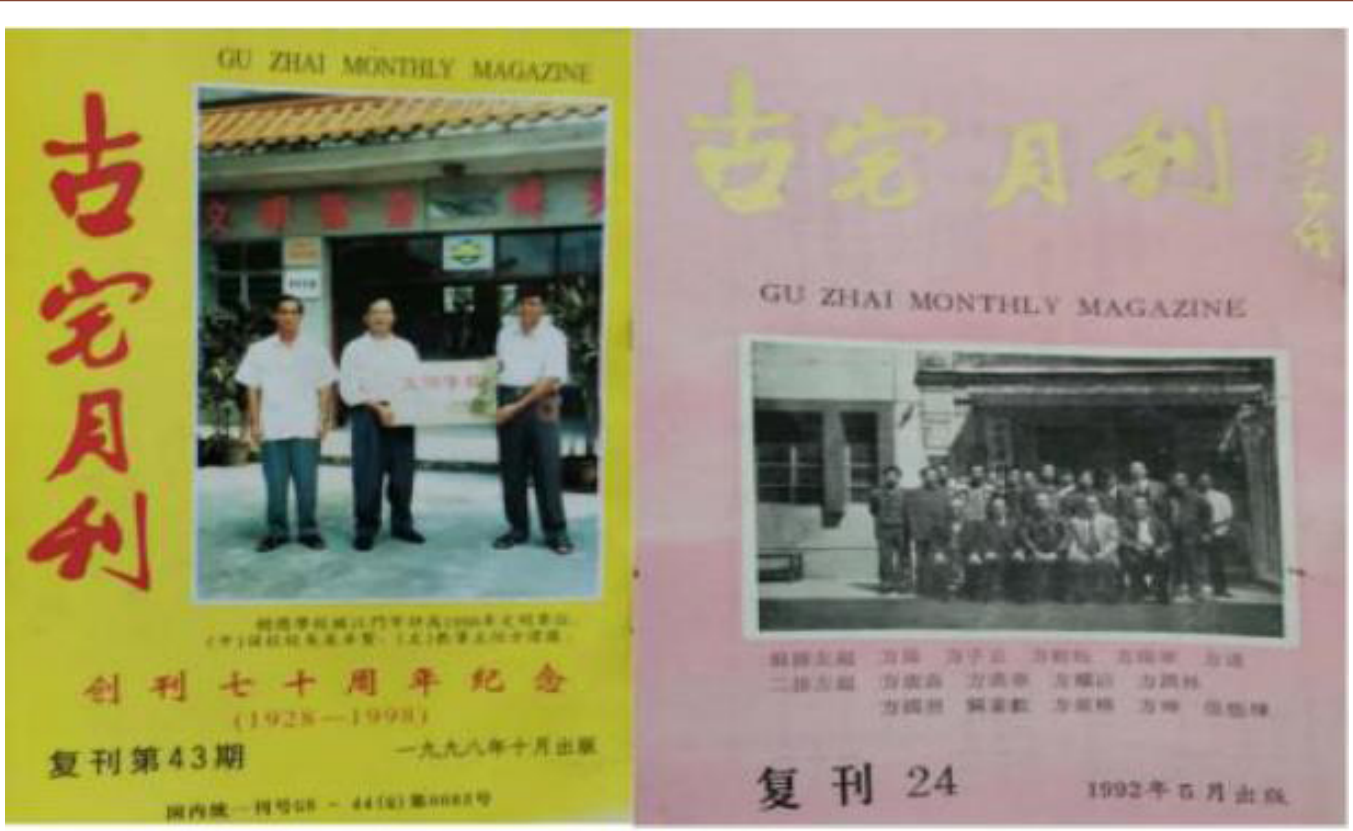

Picture 2: Guzhai Monthly. 


\section{Reconstruction of the Sense of Place in World Cultural Heritage Sites}

"From the grassroots point of view, Chinese society is nativity." This is Mr. Fei Xiaotong's judgment of Chinese society in the 1940s. In recent years, under the background of globalization and urbanization, the rural society has gradually evolved into a divorced society, and a large number of farmers have left the countryside and entered the city. Under the environment of materialization, marketization, utilitarianism and money supremacy in cities, it is difficult for farmers to find their own emotional belongings and fall into the identity dilemma under the dual social structure of urban and rural areas. The original folk customs and value system in rural areas are gradually disappearing and collapsing, and the cavitation's in rural values are becoming increasingly serious. The traditional value system is facing transformation and reconstruction in the process of social transformation, and the rural society is declining day by day. However, when Chinese society is fading away from its original local character, the formation of contemporary Chinese cultural heritage discourse system is related to the shaping of modern representation of "vernacular", which develops a modern understanding and expression practice of local sense [19].

In December 2013, Chinese Central Working Conference on urbanization proposed: "let residents see the mountains, see the water, and remember their nostalgia." Cultural nostalgia is characterized by the relationship between people and their hometown, which is a sense of place bursting out in strange land with local stigmas and agglomerating local collective memory. At the same time, by answering the question of "who am I" and "where I am", the sense of place enables people to find their own position in the coordinate system of the modern two-dimensional societies of urban and rural areas. The proposal of "visible nostalgia" requires us to pay attention to people's inner spiritual needs from the perspective of human care and humanistic feelings, awaken the local collective memory, and transform the feelings rooted in the countryside into the original power of rural cultural transformation and reconstruction, and make it possible for the backward and closed rural areas to become the source of social value and spiritual sustenance. In this sense, it is an important practice to reconstruct the sense of place by cultural heritage exhibition in response to the transformation of social modernity.

Starting from 2000, Kaiping city began to apply for world heritage for eight years. By the end of June 2007, Kaiping Diaolou and village project successfully passed the vote of the 31st World Heritage conference held in New Zealand and was officially listed in the world heritage list. On the one hand, the heritage project has promoted the in-depth excavation and carding of Kaiping local history, and the culture of overseas Chinese hometown has been refined and shaped as a heritage. The exhibition of heritage shows the traditional customs, values and beliefs, folk stories and so on in a field through video playback, optical projection, picture display, etc., and reproduces the collective memory in the form of material placement, pattern reproduction and text evidence, showing the common past and shared memory of the place. In the process of contact with these heritages, villagers share the local cultural memory; gain a sense of historical participation and subjective existence, so as to establish a continuous connection between ancestors and future generations [20]. Therefore, heritage has become a link between the "past" and "present" in rural areas. In this sense, Kaiping Diaolou and the village as well as the overseas Chinese culture represented by it have been retained and widely spread, and the collective memory of the village has been re preserved and reposed substantially, which has extended the modern significance of the rural value and strengthened the villagers' recognition and attachment to the place. On the other hand, heritage reshapes the original cultural value and villagers' concept.

The Diaolou used to be a symbol of triumphant return home of overseas Chinese in Kaiping. It was also an important way for overseas Chinese to show off their personal achievements, and also a symbol of clan and local strength. However, with the passage of time, Kaiping Diaolou once became the "old house" and "broken house" in the hearts of villagers. After becoming a heritage, Kaiping Diaolou gained new economic and cultural values, and also affected the original values of local people.

From the perspective of external forces, the shaping of the power class, the spread of mass media, the construction of heritage framework, the process of historical evolution and development, and the promotion of commercial and economic interests, reshape and enrich the connotation of the place. Before becoming a world cultural heritage, it is difficult for villagers to find the potential value of Diaolou and village. However, with the gradual deepening of heritage declaration process and the improvement of local tourism scale, the rural environment and economy have been improved. More and more tourists visit the watchtower and rural landscape, forcing villagers to re-examine their values of cultural heritage. From the perspective of the internal force of building a sense of place, villagers often take the initiative to recommend and introduce Diaolou to tourists. It is not difficult to understand that Kaiping Diaolou has become a local name card displayed by local villagers to foreign tourists. "Tourists come to Kaiping to see the Diaolou" has become the subconscious of local villagers; the value change of place, space and landscape affects the construction of individual sense of place. As a villager of Sangyuan village said: "it is no longer necessary to rebuild the ancestral hall (Hongyifang Ancestral Hall in Sangyuan Village), and people want to change it into a local restaurant..." Obviously, the clan culture represented by ancestral temples is declining and diluted by the trend of economic development. In a word, the countryside has been continuously constructed in different times, and the rural value has also been transformed and reconstructed (Picture 3). 


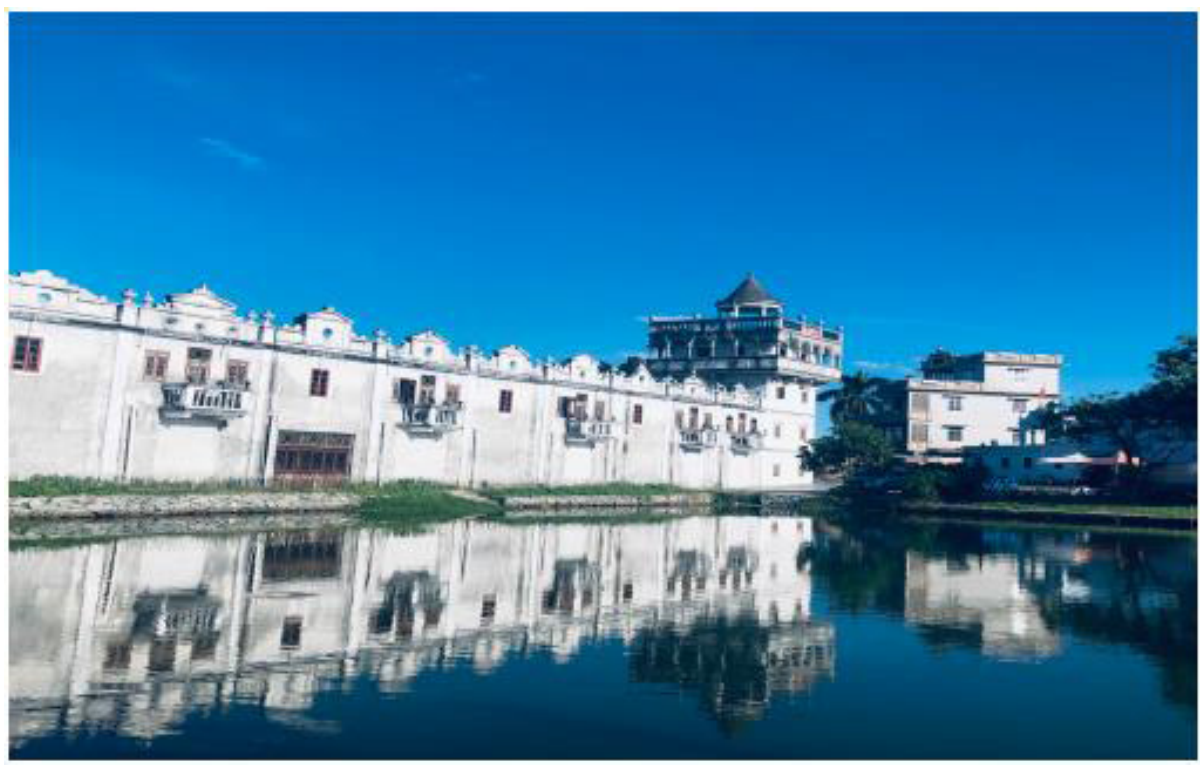

Picture 3: Kaiping Diaolou.

\section{Conclusion and Discussion}

Based on the perspective of the sense of place, this paper explores the ways of shaping the sense of place in Kaiping Guzhai area, especially Tangkou village, Sangyuan village and Miaobian village, by using the methods of network data and local literature collection, semi-structured interview and in-depth interview. Then it analyzes the interactive mechanism of the emotional communication between Fang's clan and local people through ancestral temples and family magazine. This paper mainly discusses the reconstruction and transformation of rural value of heritage sites in the process of Kaiping's transformation from Qiaoxiang to the world cultural heritage site. The main conclusions are as follows:

The ancestral hall bears the function of clan collective activities, is the daily space and local value symbol of villagers' emotional communication. The villagers' repeated chatting habits enrich the local context, forming a unique collective memory, and then passing on the family memory with clan history mark between generations. Personal feelings and identity of clansmen at home and abroad can be mutually beneficial and exchanged through rituals and typical hometown symbols (lantern banquet, family magazine, etc.), so that the sharers of clan affairs can better integrate into the collective, and then obtain a sense of belonging and cohesion. As an important ritual activity to reflect the sense of clan locality, the lantern banquet is a channel for the villagers to construct self-identity through clan identity. Through this clan activity, Fang family members maintain the identity of clans at home and abroad to their hometown. At the same time, people who have left their hometown to work and those who have gone abroad renew their own clan belief and identity in the festival space and atmosphere of the lantern banquet.

Meanwhile, the village photo after the banquet became the material witness of this process and continued to affect the emotional space of the villagers and maintain the stability of the clan. Guzhai monthly is an important channel for information communication between local overseas Chinese communities and overseas Chinese communities. It made local villagers, overseas Chinese and their family members understand the basic situation of both sides through text reading. It also connects the Fang people worldwide gets emotional connection through writing practice, thus building a direct economic and cultural channel to Qiaoxiang. Based on the clan identity, it realized the construction and maintenance of local meaning and completed the self-identity and positioning at the individual level.

Cultural heritage projects not only promote the revitalization of rural value and enhance the villagers' recognition of the village, but also weaken the original value of the village. It can be seen that the value of rural areas is not static, it continues to transform and reconstruct in different times. Sponsored by the Federation of overseas Chinese and organized by Jiangmen Federation of overseas Chinese, the activities of Chinese youth seeking roots in China are one of the important areas for cultural exchange between overseas Chinese and their hometown. From the revival of clans in South China to the revitalization of Jiangmen Qiaoxiang, the strategic significance of Jiangmen as a national "General Overseas Chinese Affairs" experimental field is re-interpreted from the perspective of national strategy and national rejuvenation. From nativity to sense of place, cultural heritage exhibition and reconstruction of sense of place is an important practice to deal with the transformation of social modernity. Thus, on the basis of the development of cultural heritage, how to ensure the construction of the value of the hometown of overseas Chinese presents a reciprocal relationship due to the continuous cultural complex, which is worth pondering. 


\section{Acknowledgement}

This project is supported by College Students' Innovation and Entrepreneurship Project (project number: 201911349301).

Authors would like to thank Prof. Jiujiang Zhu for his guidance of writing this paper, and also for his financial support through the project "High Education funding of Guangdong Province: 2018KZDXM072".

\section{Conflict of Interest}

No conflict of interest.

\section{References}

1. Li Jia (2012) Change of the Local Society and Recreation of Rural Cultures. China Rural Survey 4: 70-75+91+95.

2. Compilation and Translation Bureau of the CPC Central Committee (2012) Selections (Anthologies) of Marx and Engels 4, Beijing Renmin Press, Beijing, China 4: 611.

3. Liao Chunhua,Yang Kunwu (2014) Identity Research of the Urban Historic District in a New Perspective. Journal of Yunnan Normal University, Humanities and Social Sciences 46(1): 49-56.

4. Sun Jiuxia, Zhou Yi (2015) Residents' place identity at heritage sites: Symbols, memories and space of the "Home of Diaolou". Geographical Research 34(12): 2381-2394.

5. Harvey D (1989) The Condition of Postmodernity. Brasil Blackwell, Oxford, England, pp. 260-283.

6. Tuan YF (1974) Topophilia: A Study of Environmental Perception. Prentice Hall, Englewood Cliffs, America. pp. 1-125.

7. Relph E (1976) Place and Placelessness, Pion, London, England, pp.34.

8. Zheng Changhui (2020) Re-Recognizing the Sense of Place in the Context of Urbanization: Literature Review on the Concept and Research Progress. Urban Studies 2020 27(5): 116-124.
9. Dai Junhui (2019) Progress of Connotation, Dimension, and Influencing Factors of Place Identity. Progress in Geography 38(5): 662-674.

10. Zhu Hong, Liu Bo (2011) Concepts Analysis and Research Implications: Sense of Place, Place Attachment and Place Identity. Journal of South China Normal University, Natural Science Edition 1: 1-8.

11. Altman I, Low SM (1992) Place Attachment. Plennum Press, New York, America.

12. Proshansky HM (1978) The City and Self-Identity. Environment and Behavior 10(2): 147-169.

13. Zhu Hong, QIAN Junhui, Chen Xiaoliang (2010) Place and Identity: The Rethink of Place of European-American Human Geography. Human Geography 25(6): 1-6.

14. Wang Min Jiang Ronghao, Zhu Hong (2017) Transnational lineage network and the construction of place meaning of Qiaoxiang. World Regional Studies 26(1): 112-123

15. Yang Tian (2017) The Interaction between Social Memory and Power. Gansu Social Sciences 3: 250-255.

16. Fei Xiaotong (2020) Rural China. Tiandi Press, Beijing, China, pp.114

17. Wang Yuanlin, Deng Minrui (2005) The Change of Lifestyle and Custom in Qiaoxiang in Modern Times: With Special Reference to Chaoshan and Wuyi.Overseas Chinese History Studies 4: 56-62.

18. Wang Minjiang Ronghao, Zhu Hong (2017) Transnational lineage network and the construction of place meaning of Qiaoxiang World Regional Studies 26(1): 112-123.

19. Zhang Yuan (2014) From "Localism" to "Sense of Place": The Modern Bearing of Cultural Heritage. Journal of Southwest University for Nationalities, Humanities and Social Sciences edition 4: 6-12.

20. Fan Youmeng, Xie Yanjun (2015) Memory, Display and Gaze: A Research on the Synergy of Protection and Utilization about Rural Cultural Heritages. Tourism Science 1: 11-24+87. 